\title{
Incidence of intracranial tumours in the Lothian region of Scotland, 1989-90
}

\author{
Carl E Counsell, Donald A Collie, Robert Grant
}

\begin{abstract}
Objective-To determine the incidence of primary and secondary intracranial tumours in the Lothian region of south east Scotland.

Methods-A population based study was performed. Patients from Lothian with incident intracranial tumours diagnosed in 1989 and 1990 (by CT or histology) were identified retrospectively using multiple sources. Differences in incidence by tumour type, age, sex, and socioeconomic status were examined.

Results-Four hundred and forty two patients with incident intracranial tumours were identified (228 primary tumours and 214 secondary tumours). The crude yearly incidences of primary and secondary tumours were 15.3 and 14.3 per 100000 respectively. The commonest primary tumours were neuroepithelial tumours $(53 \cdot 5 \%)$, meningeal tumours (19.5\%), and sellar tumours (16.5\%). About $50 \%$ of patients with secondary tumours had an underlying lung cancer. The incidence of primary and secondary tumours increased markedly with age. Meningeal tumours were more common in women, and neuroepithelial tumours were more common in those who lived in more affluent areas.

Conclusions-The incidence rates of primary and secondary intracranial tumours in Lothian were more than twice those previously reported in the United Kingdom. Intracranial tumours are a significant cause of morbidity and mortality in the United Kingdom, and further research into their aetiology and treatment is urgently required.
\end{abstract}

\section{$(\Im$ Neurol Neurosurg Psychiatry 1996;61:143-150)}

Keywords: Intracranial tumours; incidence; epidemiology

Accurate data on the incidence of intracranial Department of Clinical Neurosciences, Western General Hospital, Crewe Road, Edinburgh EH4 2XU, UK

Correspondence to: Dr Carl Counsell.

Received 25 October 1995 and in revised form 14 February 1996 Accepted 4 April 1996 have been increasing in several countries over the past 50 years, particularly in elderly people. $^{3-8}$ Some authors have argued that the increase is artefactual due to: (a) the introduction of simpler, more accurate diagnostic techniques such as CT; $(b)$ the increase in the number of neurologists in some countries; (c) the improved care of elderly people; (d) changes in coding classification; and (e) misclassification of secondary brain tumours as primary tumours. ${ }^{7-9} 10$ Others have argued that this cannot explain all of the apparent increase. ${ }^{3411}$

Accurate and reliable incidence studies are therefore required to: (a) allow adequate assessment of the true burden of intracranial tumours in society; $(b)$ allow appropriate planning of cancer services for these patients in the future; $(c)$ define whether the increase in incidence is real and continuing or not; and $(d)$ enhance epidemiological research into possible risk factors for intracranial cancer. However, there have been few studies of the incidence of intracranial tumours and only three of these have been performed in the United Kingdom. Two predated the widespread use of $\mathrm{CT}^{13}$; the other was restricted to patients seen in one neurosurgical department in south Wales. ${ }^{14} \mathrm{~A}$ population based incidence study was therefore performed in the Lothian region of Scotland to describe the overall incidence of both primary and secondary intracranial tumours. A report of the incidence of gliomas in the working population has been published elsewhere. ${ }^{15}$

\section{Subjects and methods}

Figure 1 shows the study area. During the study period, the Lothian region was served by one neurology department (providing services at the Western General Hospital, the Royal Infirmary in Edinburgh, and St John's Hospital in Livingston), one neurosurgery department, one neuropathology laboratory, one oncology and radiotherapy department (all based at the Western General Hospital), two endocrine departments, and two paediatric departments. Three hospitals in Lothian had CT machines, two of which had been available for over 10 years (at the Western General Hospital and the Royal Infirmary in Edinburgh) and one of which was installed early in 1990 (at St John's Hospital, Livingston). One hospital (the Royal Infirmary) could perform MRI. Patients from Lothian with suspected intracranial tumours are unlikely to have been referred outside the 


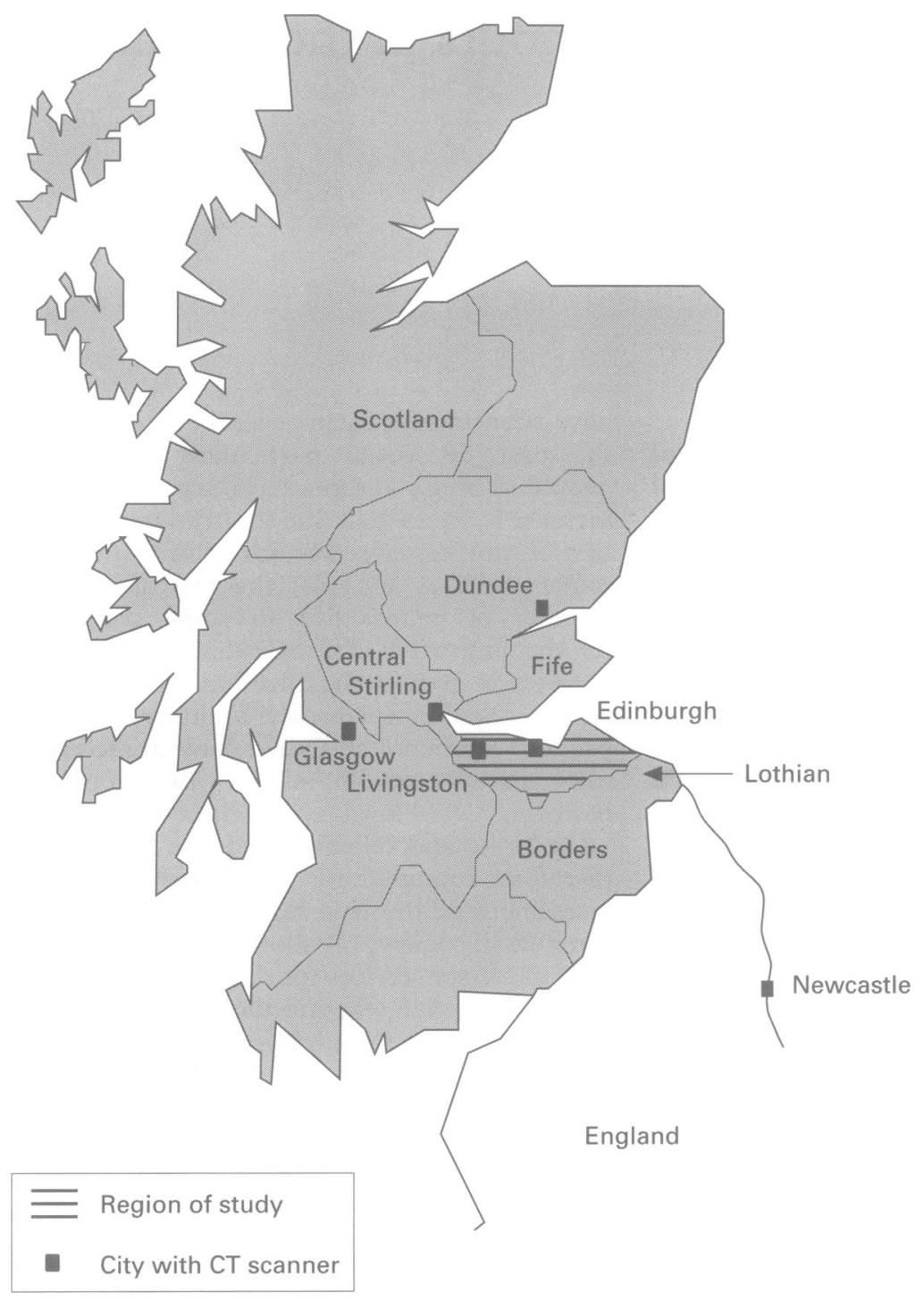

Figure 1 A map of the study area.

area for further investigation. For patients who lived anywhere in Lothian, the nearest CT machine was always in Lothian (see fig 1), and the regional neurosciences centre was based in Edinburgh.

Table 1 Types of tumour identified and percentage with histological confirmation

\begin{tabular}{lcc}
\hline WHO tumour type & $\begin{array}{l}\text { No of } \\
\text { patients }\end{array}$ & $\begin{array}{l}\text { No (\%) } \\
\text { with histology }\end{array}$ \\
\hline All primary tumours & 228 & $158(69)$ \\
Neuroepithelial tumours & 122 & $88(72)$ \\
Astrocytic & 99 & \\
Oligodendroglial & 6 & \\
Mixed glioma & 5 & \\
Ependymomal & 4 & \\
Pineal & 3 & $35(78)$ \\
Embryonal & 5 & \\
Meningeal tumours & 45 & \\
Meningioma & 41 & \\
Haemangioblastoma & 2 & $18(47)$ \\
Haemangiopericytoma & 1 & \\
Lipoma & 1 & $8(80)$ \\
Sellar region & 38 & $7(70)$ \\
Pituitary & 35 & $1(100)$ \\
Craniopharyngioma & 3 & $2(100)$ \\
Cranial nerve tumours & 10 & $24(11)$ \\
Acoustic schwannoma & 10 & $6(5)$ \\
Primary CNS lymphomas & 10 & \\
Germ cell tumours & 1 & \\
Cysts/tumour-like lesions & 2 & \\
All secondary tumours & 214 & \\
Single & 95 & 19 \\
Multiple & 119 & \\
\hline
\end{tabular}

DEFINITIONS

Incident cases

All patients who were normally resident in the Lothian region (as defined by an $\mathrm{EH}$ postcode) and in whom the diagnosis of any new intracranial tumour was made between 1 January 1989 and 31 December 1990 were included, whether symptomatic or asymptomatic. Patients with recurrent intracranial tumours were excluded. The date of diagnosis was taken as either the date of the first abnormal CT or MRI (whichever was first), or the date of necropsy in those who did not have a scan. Patients with a purely clinical diagnosis of intracranial tumour in whom there was no neuroradiology or histology were excluded as were spinal tumours and primary tumours of the retina.

\section{Intracranial tumours}

The intracranial tumours were classified into eight categories (table 1) on the basis of the second World Health Organisation (WHO) classification. ${ }^{16}$ Tumours were classified, where possible, on the basis of histology, all of which was performed in the neuropathology department at the Western General Hospital. If no histology was available, then the tumours were classified on the basis of their appearance on CT or MRI, their clinical course, and, in the case of pituitary tumours, an appropriately investigated endocrine abnormality. In the absence of histology, single hemispheric lesions in patients with no history of systemic cancer were usually classified as either gliomas, meningiomas, or solitary metastases, and multiple lesions were usually presumed to be metastases. A previous study from the Western General Hospital showed that the CT diagnosis of a solitary glioma or meningioma was correct in $90 \%$ of cases but that CT diagnosis of a solitary metastasis was correct in only $50 \%$ of cases biopsied, the other $50 \%$ of cases being gliomas. ${ }^{17}$ In addition, a recent study of multifocal brain lesions in patients with no history of systemic cancer showed that $60 \%$ of such lesions were found to be neuroepithelial tumours on biopsy. ${ }^{18} \mathrm{~A}$ separate analysis was therefore planned in which $50 \%$ of those with a radiological diagnosis of solitary metastasis and no known primary cancer, and $60 \%$ of those with a radiological diagnosis of multiple metastases and no known primary cancer were reclassified as gliomas.

\section{Socioeconomic status}

The incidence of intracranial tumours may vary by social class. ${ }^{19}$ In this study, socioeconomic status was assigned to each patient on the basis of the Carstairs deprivation score for the postcode sector of their place of residence (see Appendix 1). ${ }^{20}$ Social class based on the patient's occupation was not used because this was not always available from the hospital notes and was difficult to define accurately in patients who were retired or not working. For the purposes of this study, the Carstairs score was divided into seven deprivation categories as previously defined, ${ }^{20}$ category 1 being the most affluent and category 7 the most deprived. 
CASE ASCERTAINMENT

To minimise the number of cases that may have been missed, multiple overlapping methods were used to identify eligible patients. The following were reviewed: (1) the reports of all cranial CT performed at the three radiology departments with CT scanners between 1 January 1989 to 31 December 1990; (2) neurology and neurosurgery discharges from 1 January 1989 to 1 April 1991 ; (3) cases attending the neuro-oncology clinic at the Western General Hospital in the two study years; (4) databases of patients attending the two endocrinology departments in the study period to identify patients with pituitary tumours; (5) neuropathology reports on brain specimens from 1 January 1989 to 31 December 1993; (6) case records of patients who had received cranial radiotherapy between 1 December 1989 and 1 April 1991; (7) details of all patients resident in Lothian who were registered in the Scottish Cancer Registry between October 1988 and April 1991 with codes relevant to intracranial tumours (see Appendix 2); (8) details of all patients resident in Lothian who were admitted to hospitals in south east Scotland between October 1988 and April 1991 and who had one of the relevant codes in their hospital discharge data were requested from the Information and Statistics Division of the Common Services Agency for the Scottish Health Service. Some of these searches were extended beyond 31 December 1990 because there may have been a delay between the time of the first abnormal CT (the incident date used in this study) and the time of hospital admission, biopsy, or radiotherapy.

\section{DATA EXTRACTION}

The case notes, CT or MRI, and histology reports of any patient identified using the above searches were traced and carefully reviewed to ensure that the diagnosis of intracranial tumour was correct, and that the diagnosis was made during the study period (for example, that there was no evidence of an abnormality on CT taken before 1989). Relevant demographic, clinical, and histological data were extracted by medically qualified staff using a standard form. If notes could not be traced, as much information as possible was extracted from the CT or histology request forms and reports. Patients who died were identified by linking the patient data to the Scottish death register which was then searched up to 31 December 1993. The data were entered into a standard computerised database (D Base IV, Borland International Inc) and a series of quality checks were performed. Any duplicate cases were identified and excluded.

\section{STATISTICAL ANALYSIS}

The population of Lothian for the study period (total 748 703: 360565 male, 388138 female) was taken as the average of the midyear estimates for 1989 and 1990 which were based on the 1981 and 1991 censuses (K Dargie, Population Branch, General Register
Office, Scotland, personal communication). The annual incidence rate was calculated as the average rate over the two study years. Crude incidence rates were calculated from the total number of cases and the total population of Lothian. In addition, when the numbers of cases were sufficient (arbitrarily defined as 10 or more cases), age and sex specific rates were calculated. Ninety five per cent confidence intervals (95\% CIs) were calculated assuming a Poisson distribution. To establish whether incidence rates varied significantly between male and female patients, the relative risk of each tumour was calculated for each sex using the Mantel-Haenszel technique to stratify for age in four bands (0-24 years, 25-44 years, 45-64 years, 65 or more years). The effect of socioeconomic status on the incidence of all primary tumours, of neuroepithelial tumours (the largest subgroup of primary tumours), and of all secondary tumours was also examined by calculating the incidence for each separate Carstairs deprivation category. The $\chi^{2}$ test for trend was used to assess whether there was a significant linear relation between incidence and age and deprivation category.

Statistical analyses were performed using the Epi Info (version 5) and SPSS (version $4 \cdot 0 \cdot 1)$ statistical packages.

ETHICS

Ethical approval was obtained from the health boards in south east Scotland to access hospital discharge data and the Scottish Cancer Registry.

\section{Results}

During the two year period, a total of 442 patients with incident intracranial tumours were identified. One hundred and fifty two patients (124 primary, 28 secondary) were identified in the Cancer Registry. Fifty three patients $(12 \%)$ were not, as far as we can tell, admitted to hospital. A further 30 patients were excluded: no notes, CT report, or histology report were available to confirm a suspicion of intracranial tumour in 23; the diagnosis was based on clinical grounds alone in five; and two patients were not resident in Lothian at the time of the diagnosis. Twenty two patients $(5 \%)$ were included on the basis of CT or histology report alone as clinical notes could not be traced. In all except two patients, the initial diagnostic investigation had been CT: in one patient, asymptomatic multiple meningiomata were found at necropsy, and another patient, who was presumed to have had a stroke, was found to have a glioblastoma at necropsy. Only two patients out of the 420 patients whose notes were available had definitely asymptomatic tumours: the patient with multiple meningiomata described above and another in whom a meningioma was found on CT which had been performed for another indication.

Table 1 shows the numbers of patients with the different types of tumour and the percentage confirmed with histology. Histology was 
Table 2 Crude incidences for intracranial tumours in Lothian

\begin{tabular}{lc}
\hline Tumour type & $\begin{array}{l}\text { Crude incidence } \\
(95 \% \text { CI })\end{array}$ \\
\hline Neuroepithelial & $8 \cdot 2(6 \cdot 8-9 \cdot 8)$ \\
Gliomas & $7 \cdot 7(6 \cdot 3-9 \cdot 2)$ \\
Meningeal & $3 \cdot 0(2 \cdot 6-4 \cdot 0)$ \\
Meningiomas & $2 \cdot 7(1 \cdot 9-3 \cdot 6)$ \\
Sellar & $2 \cdot 5(1 \cdot 7-3 \cdot 3)$ \\
Pituitary adenoma & $2 \cdot 3(1 \cdot 6-3 \cdot 2)$ \\
Cranial nerve & $0 \cdot 7(0 \cdot 3-1 \cdot 2)$ \\
CNS lymphoma & $0 \cdot 7(0 \cdot 3-1 \cdot 2)$ \\
Germ cell & $0 \cdot 1(0 \cdot 0-0 \cdot 4)$ \\
Cystic lesions & $0 \cdot 1(0 \cdot 0-0 \cdot 5)$ \\
All primary tumours & $15 \cdot 3(13 \cdot 4-17 \cdot 4)$ \\
Secondary tumours & $14 \cdot 3(12 \cdot 4-16 \cdot 3)$ \\
\hline
\end{tabular}

^Expressed as rates per 100000 per year.

available for 182 (41\%) patients overall (169 biopsies, 13 necropsies), and for $69 \%$ of primary tumours and $11 \%$ of secondary tumours. The overall necropsy rate was low: 326 patients died during follow up of at least three years, and only 18 had necropsies (6\%). Two hundred and twenty eight cases of primary intracranial tumour were identified $(52 \%$ of all tumours, $95 \%$ CI $47 \%-56 \%$ ). Of these $53.5 \%$ were neuroepithelial tumours, $19.5 \%$ were meningeal tumours, $16.5 \%$ were sellar tumours, $4.5 \%$ were cranial nerve tumours, $4.5 \%$ were primary CNS lymphomas, $1 \%$ were cystic lesions, and $0.5 \%$ were germ cell tumours. Most (93\%) of the neuroepithelial tumours were gliomas, of which $76 \%$ (86/114) were classified as high grade (glioblastoma, anaplastic astrocytoma, anaplastic oligodendroglioma). Of the 35 patients with pituitary tumours, 20 had non-functioning tumours, 12

Figure 2 Age distribution of patients with intracranial tumours.

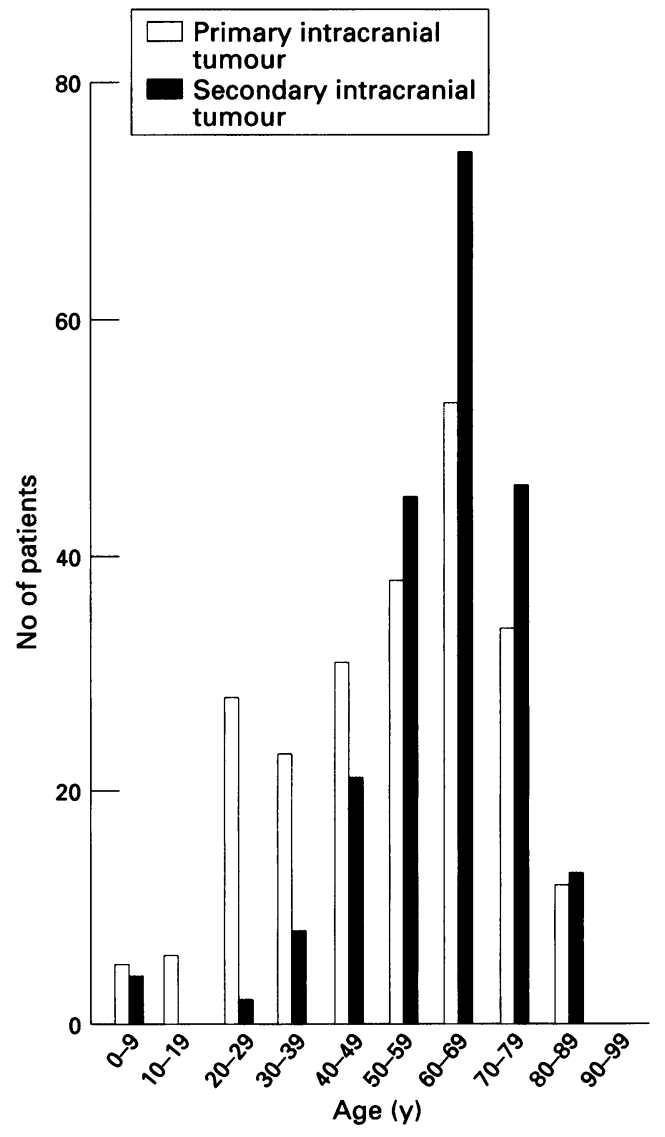

had prolactinomas, and one each had a chromophobic tumour, a growth hormone secreting tumour, and an adenocarcinoma. Only one of the 10 patients with a primary CNS lymphoma was known to have AIDS. The single germ cell tumour was a pineal germinoma, and the two cystic lesions were a colloid cyst of the third ventricle and a dermoid cyst.

Secondary intracranial tumours were diagnosed in 214 patients ( $48 \%$ of all tumours, 95\% CI $44 \%-53 \%)$. In four patients the secondary tumour was a direct extension from a local tumour, whereas in 210 patients the secondary tumour had metastasised from a distant primary tumour (lung cancer 112 cases (53\%), unknown primary site 29 cases (14\%), breast cancer 27 cases (13\%), malignant melanoma 16 cases $(8 \%)$, bowel cancer seven cases $(3 \%)$, renal cancer four cases $(2 \%)$, haematological cancers (two non-Hodgkin's lymphomas, one acute myeloid leukaemia) three cases $(1 \%)$, uterine cancer two cases $(1 \%)$, and one case each of adrenal cancer, bladder cancer, neuroblastoma of the eye, laryngeal cancer, oesophageal cancer, pancreatic cancer, prostatic cancer, rhabdomyosarcoma, sacral tumour of unknown type, and testicular teratoma). In 24 of the cases with an unknown primary tumour, there was no evidence of systemic cancer and the diagnosis of a secondary tumour was made on the basis of the CT appearance alone. Thirteen of these patients had multiple lesions and 11 had a single lesion on CT.

\section{INCIDENCE}

Table 2 gives the crude incidences for Lothian for each tumour type. If, in patients with no known primary cancer, $50 \%$ of solitary metastases and $60 \%$ of multiple metastases diagnosed radiologically were, in fact, gliomas, 13 patients in this study may have been misclassified as having secondary intracranial tumours. Reclassifying these as gliomas, the incidence of neuroepithelial tumours increased slightly to $9 \cdot 1$ per 100000 per year $(95 \%$ CI $7 \cdot 6-10 \cdot 7)$.

AGE RELATED DIFFERENCES IN INCIDENCE

Figure 2 shows the age distributions of patients with primary and secondary intracranial tumours. Patients with primary tumours were significantly younger than those with secondary tumours (mean age 53 (SD 20) years $v 61$ (SD 15) years; Student's $t$ test, $P<0.0001)$. The average ages of patients with different types of primary tumour were: neuroepithelial tumours 53 (SD 21), range 1-86 years; meningeal tumours 58 (SD 16), range 22-89 years; sellar tumours 46 (SD 18), range 17-84 years; cranial nerve tumours 55 (SD 14), range 39-86 years; primary CNS lymphoma 58 (SD 20), range 22-79 years.

Table 3 gives age specific incidence rates of each tumour type. Analyses and interpretation of these data were limited by the few patients in many of the groups, especially in those aged under 14 and over 85 years, such that the $95 \%$ CIs were often very wide. The incidence of all primary tumours increased with age until a peak between the age of 65 and $74\left(\chi^{2}\right.$ trend 
Table 3 Age specific incidence rates for each tumour type

\begin{tabular}{|c|c|c|c|c|c|c|c|c|c|}
\hline & \multicolumn{9}{|l|}{ Age (y) } \\
\hline & $0-14$ & $15-24$ & $25-34$ & $35-44$ & $45-54$ & $55-64$ & $65-74$ & $75-84$ & $\geqslant 85$ \\
\hline All primary & $\begin{array}{l}3 \cdot 5 \\
(1 \cdot 6-6 \cdot 6)\end{array}$ & $\begin{array}{l}6 \cdot 1 \\
(3 \cdot 4-10 \cdot 1)\end{array}$ & $\begin{array}{l}10 \cdot 4 \\
(6 \cdot 8-15 \cdot 2)\end{array}$ & $\begin{array}{l}13 \cdot 7 \\
(9 \cdot 1-19 \cdot 8)\end{array}$ & $\begin{array}{l}18 \cdot 3 \\
(12 \cdot 4-26 \cdot 1)\end{array}$ & $\begin{array}{l}29 \cdot 7 \\
(21 \cdot 6-39 \cdot 7)\end{array}$ & $\begin{array}{l}36 \cdot 9 \\
(27 \cdot 0-49 \cdot 2)\end{array}$ & $\begin{array}{l}33 \cdot 4 \\
(21 \cdot 8-49 \cdot 0)\end{array}$ & $\begin{array}{l}19 \cdot 2 \\
(5 \cdot 2-49 \cdot 2)\end{array}$ \\
\hline Neuroepithelial & $\begin{array}{l}3 \cdot 5 \\
(1 \cdot 6-6 \cdot 6)\end{array}$ & $\begin{array}{l}2 \cdot 9 \\
(1 \cdot 1-5 \cdot 9)\end{array}$ & $\begin{array}{l}3 \cdot 6 \\
(1 \cdot 6-6 \cdot 8)\end{array}$ & $\begin{array}{l}7 \cdot 3 \\
(4 \cdot 1-12 \cdot 1)\end{array}$ & $\begin{array}{l}8 \cdot 5 \\
(4 \cdot 7-14 \cdot 3)\end{array}$ & $\begin{array}{l}15 \cdot 2 \\
(9 \cdot 6-22 \cdot 7)\end{array}$ & $\begin{array}{l}24 \cdot 0 \\
(16 \cdot 2-34 \cdot 3)\end{array}$ & $\begin{array}{l}18 \cdot 0 \\
(9 \cdot 8-30 \cdot 2)\end{array}$ & $\begin{array}{l}9 \cdot 6 \\
(1 \cdot 1-34 \cdot 7)\end{array}$ \\
\hline Meningeal & $\begin{array}{l}0 \cdot 0 \\
(0 \cdot 0-1 \cdot 4)\end{array}$ & $\begin{array}{l}0 \cdot 4 \\
(0 \cdot 0-2 \cdot 3)\end{array}$ & $\begin{array}{l}1 \cdot 6 \\
(0 \cdot 4-4 \cdot 1)\end{array}$ & $\begin{array}{l}2 \cdot 4 \\
(0 \cdot 8-5 \cdot 7)\end{array}$ & $\begin{array}{l}4 \cdot 9 \\
(2 \cdot 1-9 \cdot 6)\end{array}$ & $\begin{array}{l}6 \cdot 6 \\
(3 \cdot 1-12 \cdot 1)\end{array}$ & $\begin{array}{l}7 \cdot 2 \\
(3 \cdot 3-13 \cdot 7)\end{array}$ & $\begin{array}{l}9 \cdot 0 \\
(3 \cdot 6-18 \cdot 5)\end{array}$ & $\begin{array}{l}4 \cdot 8 \\
(0 \cdot 1-26 \cdot 8)\end{array}$ \\
\hline Sellar & $\begin{array}{l}0 \cdot 0 \\
(0 \cdot 0-1 \cdot 4)\end{array}$ & $\begin{array}{l}1 \cdot 6 \\
(0 \cdot 4-4 \cdot 2)\end{array}$ & $\begin{array}{l}4 \cdot 4 \\
(2 \cdot 2-7 \cdot 9)\end{array}$ & $\begin{array}{l}2 \cdot 9 \\
(1 \cdot 1-6 \cdot 4)\end{array}$ & $\begin{array}{l}1 \cdot 2 \\
(0 \cdot 1-4 \cdot 4)\end{array}$ & $\begin{array}{l}5 \cdot 9 \\
(2 \cdot 7-11 \cdot 2)\end{array}$ & $\begin{array}{l}2 \cdot 4 \\
(0 \cdot 5-7 \cdot 0)\end{array}$ & $\begin{array}{l}3 \cdot 8 \\
(0 \cdot 8-11 \cdot 3)\end{array}$ & $\begin{array}{l}0 \cdot 0 \\
(0 \cdot 0-17 \cdot 7)\end{array}$ \\
\hline Cranial nerve & $\begin{array}{l}0 \cdot 0 \\
(0 \cdot 0-1 \cdot 4)\end{array}$ & $\begin{array}{l}0 \cdot 0 \\
(0 \cdot 0-1 \cdot 5)\end{array}$ & $\begin{array}{l}0.0 \\
(0 \cdot 0-1 \cdot 5)\end{array}$ & $\begin{array}{l}1 \cdot 0 \\
(0 \cdot 1-3 \cdot 5)\end{array}$ & $\begin{array}{l}3 \cdot 1 \\
(1 \cdot 0-7 \cdot 1)\end{array}$ & $\begin{array}{l}0 \cdot 6 \\
(0 \cdot 0-3 \cdot 7)\end{array}$ & $\begin{array}{l}0 \cdot 8 \\
(0 \cdot 0-4 \cdot 5)\end{array}$ & $\begin{array}{l}0 \cdot 0 \\
(0 \cdot 0-4 \cdot 7)\end{array}$ & $\begin{array}{l}4 \cdot 8 \\
(0 \cdot 1-26 \cdot 8)\end{array}$ \\
\hline CNS lymphoma & $\begin{array}{l}0.0 \\
(0 \cdot 0-1 \cdot 4)\end{array}$ & $\begin{array}{l}0 \cdot 4 \\
(0 \cdot 0-2 \cdot 3)\end{array}$ & $\begin{array}{l}0 \cdot 4 \\
(0 \cdot 0-2 \cdot 2)\end{array}$ & $\begin{array}{l}0.0 \\
(0 \cdot 0-1 \cdot 8)\end{array}$ & $\begin{array}{l}0.6 \\
(0 \cdot 0-3 \cdot 4)\end{array}$ & $\begin{array}{l}1 \cdot 3 \\
(0 \cdot 1-4 \cdot 7)\end{array}$ & $\begin{array}{l}2 \cdot 4 \\
(0 \cdot 5-7 \cdot 0)\end{array}$ & $\begin{array}{l}2 \cdot 6 \\
(0 \cdot 3-9 \cdot 3)\end{array}$ & $\begin{array}{l}0.0 \\
(0 \cdot 0-17 \cdot 7)\end{array}$ \\
\hline All secondary & $\begin{array}{l}1 \cdot 5 \\
(0 \cdot 4-3 \cdot 9)\end{array}$ & $\begin{array}{l}0 \cdot 4 \\
(0 \cdot 0-2 \cdot 3)\end{array}$ & $\begin{array}{l}2 \cdot 0 \\
(0 \cdot 6-4 \cdot 7)\end{array}$ & $\begin{array}{l}7 \cdot 8 \\
(4 \cdot 5-12 \cdot 7)\end{array}$ & $\begin{array}{l}19 \cdot 5 \\
(13 \cdot 4-27 \cdot 6)\end{array}$ & $\begin{array}{l}39 \cdot 5 \\
(30 \cdot 2-50 \cdot 9)\end{array}$ & $\begin{array}{l}53 \cdot 7 \\
(41 \cdot 6-68 \cdot 2)\end{array}$ & $\begin{array}{l}36 \cdot 0 \\
(23 \cdot 9-52 \cdot 0)\end{array}$ & $\begin{array}{l}4 \cdot 8 \\
(0 \cdot 1-26 \cdot 8)\end{array}$ \\
\hline
\end{tabular}

Values are incidence/100 000/year (95\% CI).

Figure 3 Relation between incidence and socioeconomic status (vertical lines are $95 \%$ CI).
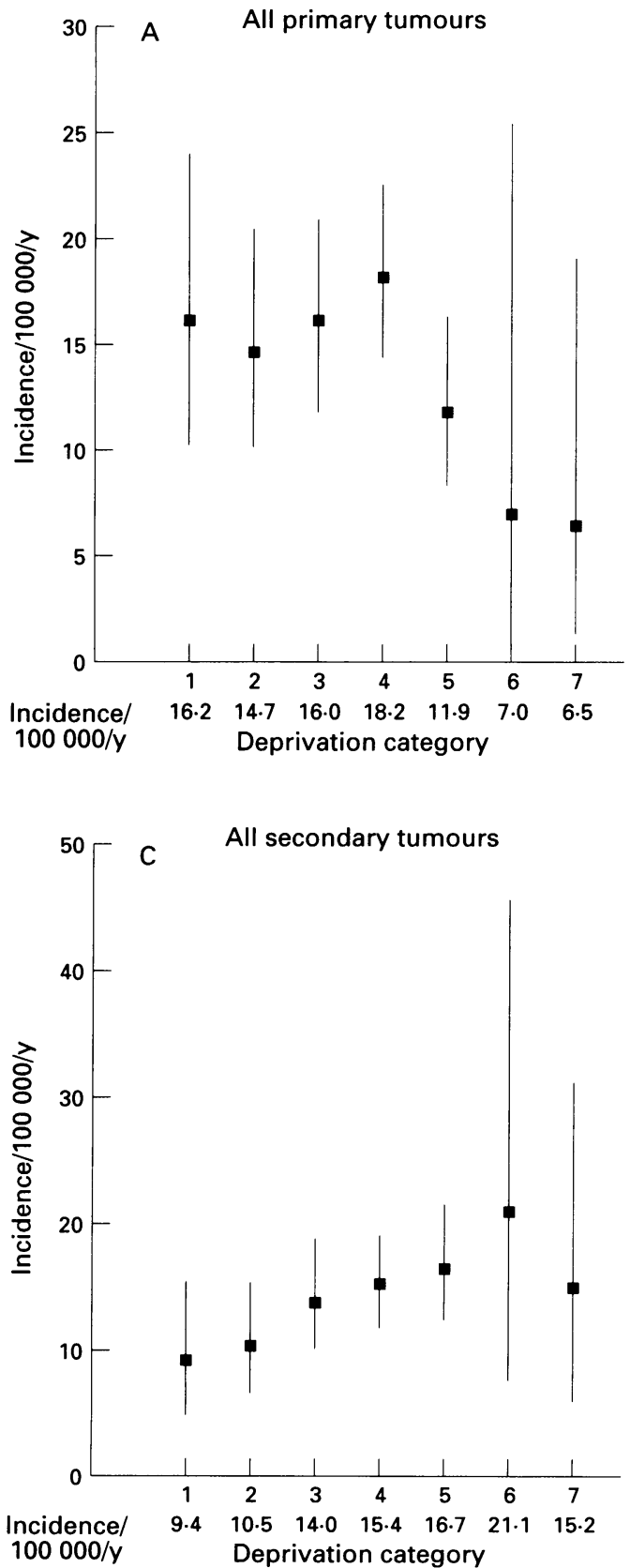

$104 \cdot 7, \mathrm{P}<0.001)$. In those aged over 74 , the incidence then decreased but the $95 \%$ CIs were wide and did not exclude the possibility of a further increase in incidence (table 3 ).

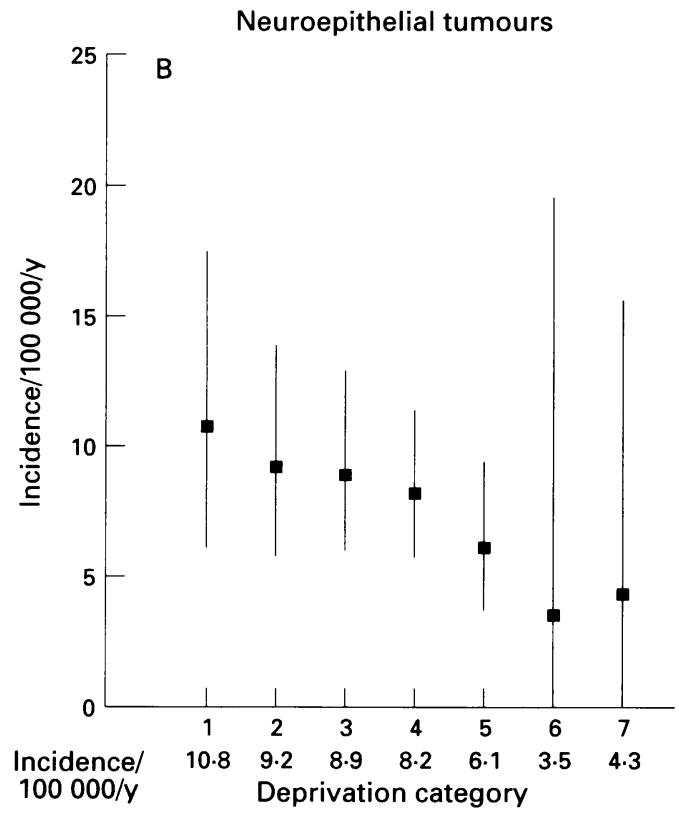

The same pattern was found if only neuroepithelial $\left(\chi_{\text {trend }}^{2} 53.6, \mathrm{P}<0.001\right)$ or meningeal tumours $\left(\chi_{\text {trend }}^{2} 37 \cdot 8, \mathrm{P}<0.001\right)$ were considered, although for meningeal tumours the peak incidence was in those aged 75 to 84 years (table 3 ). There was the suggestion of a small second peak in incidence of neuroepithelial tumours in those aged under 14. There was no obvious relation between age and the incidence of sellar tumours $\left(\chi_{\text {trend }}^{2} 3 \cdot 5, \mathrm{P}=\right.$ 0.06 ), and there were too few tumours in the other categories to identify any association between age and incidence.

The relation between age and the incidence of all secondary tumours seemed to be slightly different from that of primary tumours. There was an exponential increase in incidence until the age of 74 years. After this there was an apparent significant decrease in the incidence, particularly in those aged over 85 years (table 4).

SEX RELATED DIFFERENCES IN INCIDENCE

Table 4 shows the age and sex specific incidences of each tumour type, along with the age standardised relative risks of tumours in male as opposed to female subjects. Once 
Table 4 Age and sex specific rates of patients with each tumour type

\begin{tabular}{|c|c|c|c|c|c|c|c|c|c|c|}
\hline \multirow[b]{3}{*}{ Tumour type } & & \multicolumn{9}{|c|}{ Age (y) } \\
\hline & & \multicolumn{2}{|c|}{$0-24$} & \multicolumn{2}{|c|}{$25-44$} & \multicolumn{2}{|c|}{$45-64$} & \multicolumn{2}{|c|}{$\geqslant 65$} & \multirow{2}{*}{$\begin{array}{l}\text { M:F Relative risk } \\
(95 \% \text { CI })\end{array}$} \\
\hline & & No & Rate $(95 \%$ CI) & No & Rate $(95 \% C I)$ & No & Rate $(95 \%$ CI) & No & Rate $(95 \%$ CI) & \\
\hline All primary & $\underset{\mathrm{F}}{\mathrm{M}}$ & $\begin{array}{l}12 \\
12\end{array}$ & $\begin{array}{l}4 \cdot 7(2 \cdot 4-8 \cdot 1) \\
4 \cdot 9(2 \cdot 5-8 \cdot 5)\end{array}$ & $\begin{array}{l}27 \\
27\end{array}$ & $\begin{array}{l}11 \cdot 9(7 \cdot 9-17 \cdot 3) \\
11 \cdot 9(7 \cdot 9-17 \cdot 3)\end{array}$ & $\begin{array}{l}33 \\
41\end{array}$ & $\begin{array}{l}21 \cdot 8(15 \cdot 0-30 \cdot 6) \\
25 \cdot 0(17 \cdot 9-33 \cdot 9)\end{array}$ & $\begin{array}{l}32 \\
44\end{array}$ & $\begin{array}{l}37 \cdot 8(25 \cdot 9-53 \cdot 3) \\
31 \cdot 7(23 \cdot 1-42 \cdot 6)\end{array}$ & $1.09(0.84-1.42)$ \\
\hline Neuroepithelial & $\underset{\mathrm{F}}{\mathrm{M}}$ & $\begin{array}{l}8 \\
8\end{array}$ & $\begin{array}{l}3 \cdot 1(1 \cdot 3-6 \cdot 1) \\
3 \cdot 2(1 \cdot 4-6 \cdot 4)\end{array}$ & $\begin{array}{l}13 \\
11\end{array}$ & $\begin{array}{l}5 \cdot 7(3 \cdot 0-9 \cdot 8) \\
4 \cdot 9(2 \cdot 4-8 \cdot 7)\end{array}$ & $\begin{array}{l}17 \\
19\end{array}$ & $\begin{array}{l}11 \cdot 2(6 \cdot 5-18 \cdot 0) \\
11 \cdot 6(7 \cdot 0-18 \cdot 1)\end{array}$ & $\begin{array}{l}23 \\
23\end{array}$ & $\begin{array}{l}27 \cdot 2(17 \cdot 2-40 \cdot 8) \\
16 \cdot 6(10 \cdot 5-24 \cdot 9)\end{array}$ & $1 \cdot 20(0 \cdot 85-1 \cdot 71)$ \\
\hline Meningeal & $\underset{\mathrm{F}}{\mathrm{M}}$ & $\begin{array}{l}0 \\
1\end{array}$ & $\begin{array}{l}0.0(0.0-1 \cdot 4) \\
0.4(0.0-2 \cdot 3)\end{array}$ & $\begin{array}{l}4 \\
5\end{array}$ & $\begin{array}{l}1 \cdot 8(0 \cdot 5-4 \cdot 5) \\
2 \cdot 2(0 \cdot 7-5 \cdot 1)\end{array}$ & $\begin{array}{r}4 \\
14\end{array}$ & $\begin{array}{l}2 \cdot 6(0 \cdot 7-6 \cdot 8) \\
8 \cdot 5(4 \cdot 7-14 \cdot 3)\end{array}$ & $\begin{array}{r}4 \\
13\end{array}$ & $\begin{array}{l}4 \cdot 7(1 \cdot 3-12 \cdot 1) \\
9 \cdot 4(5 \cdot 0-16 \cdot 0)\end{array}$ & $0.45(0.23-0.87)$ \\
\hline Sellar & $\underset{\mathbf{F}}{\mathbf{M}}$ & $\begin{array}{l}2 \\
2\end{array}$ & $\begin{array}{l}0 \cdot 8(0 \cdot 1-2 \cdot 8) \\
0 \cdot 8(0 \cdot 1-2 \cdot 9)\end{array}$ & $\begin{array}{r}7 \\
10\end{array}$ & $\begin{array}{l}3 \cdot 1(1 \cdot 2-6 \cdot 3) \\
4 \cdot 4(2 \cdot 1-8 \cdot 1)\end{array}$ & $\begin{array}{l}5 \\
6\end{array}$ & $\begin{array}{l}3 \cdot 3(1 \cdot 1-7 \cdot 7) \\
3 \cdot 7(1 \cdot 3-8 \cdot 0)\end{array}$ & $\begin{array}{l}3 \\
3\end{array}$ & $\begin{array}{l}3 \cdot 5(0 \cdot 7-10 \cdot 4) \\
2 \cdot 2(0 \cdot 4-6 \cdot 3)\end{array}$ & $0.89(0.47-1.68)$ \\
\hline Cranial nerve & $\underset{\mathbf{F}}{\mathbf{M}}$ & $\begin{array}{l}0 \\
0\end{array}$ & $\begin{array}{l}0.0(0.0-1.4) \\
0.0(0.0-1.5)\end{array}$ & $\begin{array}{l}1 \\
1\end{array}$ & $\begin{array}{l}0.4(0.0-2 \cdot 4) \\
0.4(0.0-2 \cdot 4)\end{array}$ & $\begin{array}{l}5 \\
1\end{array}$ & $\begin{array}{l}3.3(1 \cdot 1-7 \cdot 7) \\
0.6(0.0-3 \cdot 4)\end{array}$ & $\begin{array}{l}0 \\
2\end{array}$ & $\begin{array}{l}0 \cdot 0(0 \cdot 0-4 \cdot 4) \\
1 \cdot 4(0 \cdot 2-5 \cdot 2)\end{array}$ & $1 \cdot 61(0.46-5 \cdot 72)$ \\
\hline CNS lymphomat & $\underset{\mathrm{F}}{\mathbf{M}}$ & $\begin{array}{l}1 \\
0\end{array}$ & $\begin{array}{l}0.4(0.0-2 \cdot 2) \\
0.0(0.0-1.5)\end{array}$ & $\begin{array}{l}1 \\
0\end{array}$ & $\begin{array}{l}0.4(0.0-2.4) \\
0.0(0.0-1.6)\end{array}$ & $\begin{array}{l}2 \\
1\end{array}$ & $\begin{array}{l}1 \cdot 3(0 \cdot 2-4 \cdot 8) \\
0 \cdot 6(0 \cdot 0-3 \cdot 4)\end{array}$ & $\begin{array}{l}2 \\
3\end{array}$ & $\begin{array}{l}2 \cdot 4(0.3-8 \cdot 5) \\
2 \cdot 2(0.4-6 \cdot 3)\end{array}$ & $1.61(0.46-5 \cdot 72)$ \\
\hline Cystsł & $\underset{\mathrm{F}}{\mathrm{M}}$ & $\begin{array}{l}1 \\
1\end{array}$ & - & $\begin{array}{l}0 \\
0\end{array}$ & - & $\begin{array}{l}0 \\
0\end{array}$ & $\overline{-}$ & $\begin{array}{l}0 \\
0\end{array}$ & - & - \\
\hline Germ cell & $\underset{\mathrm{F}}{\mathrm{M}}$ & $\begin{array}{l}0 \\
0\end{array}$ & - & $\begin{array}{l}1 \\
0\end{array}$ & - & $\begin{array}{l}0 \\
0\end{array}$ & - & $\begin{array}{l}0 \\
0\end{array}$ & $\overline{-}$ & - \\
\hline All secondary & $\underset{\mathbf{F}}{\mathbf{M}}$ & $\begin{array}{l}2 \\
3\end{array}$ & $\begin{array}{l}0 \cdot 8(0 \cdot 1-2 \cdot 8) \\
1 \cdot 2(0 \cdot 3-3 \cdot 6)\end{array}$ & $\begin{array}{r}2 \\
19\end{array}$ & $\begin{array}{l}0 \cdot 9(0 \cdot 1-3 \cdot 2) \\
8 \cdot 4(5 \cdot 0-13 \cdot 1)\end{array}$ & $\begin{array}{l}45 \\
47\end{array}$ & $\begin{array}{l}29 \cdot 7(21 \cdot 7-39 \cdot 8) \\
28 \cdot 6(21 \cdot 0-38 \cdot 1)\end{array}$ & $\begin{array}{l}53 \\
43\end{array}$ & $\begin{array}{l}62 \cdot 6(46 \cdot 9-81 \cdot 9) \\
31 \cdot 0(22 \cdot 4-41 \cdot 8)\end{array}$ & $1 \cdot 17(0.90-1 \cdot 52)$ \\
\hline
\end{tabular}

* Relative risk stratified for age using Mantel-Haenszel analysis.

Numbers too small to allow Mantel-Haenszel analysis for M:F relative risk. Unstratified relative risk calculated.

$\ddagger$ Age-sex specific rates not calculated because of very small numbers.

again, the numbers of tumours in most classes were small and, therefore, real differences may have been missed. There were no significant differences between the sexes in the incidence of all primary or secondary tumours, or in most of the subtypes of primary tumour. However, meningeal tumours were significantly more frequent in females than in males $(2 \cdot 2: 1)$.

\section{SOCIOECONOMIC STATUS AND INCIDENCE}

Figure 3 shows the incidence of primary, neuroepithelial, and secondary tumours in each of the seven deprivation category areas. The apparent trend for the incidence of all primary intracranial tumours to be highest in the most affluent areas was not statistically significant $\left(\chi_{\text {trend }}^{2} 0 \cdot 16, P=0 \cdot 69\right)$. However, there were significant linear relations between the incidence of neuroepithelial tumours and secondary tumours and deprivation category. The incidence of neuroepithelial tumours was $2 \cdot 3$ times higher in areas of greatest affluence (category 1 or 2 ) compared with the least affluent areas (category 6 or 7$)\left(\chi_{\text {trend }}^{2} 4.56, P=0.03\right.$ ). For secondary intracranial tumours, the reverse relation was seen: the incidence was about twice as high in the least affluent areas compared with the most affluent areas $\left(\chi_{\text {trend }}^{2}\right.$ $6 \cdot 18, P=0 \cdot 01$ ).

\section{Discussion}

The incidence of primary and secondary intracranial tumours in this study was two to three times greater than in previous studies in the United Kingdom, but less than was found in a recent study from northern Italy. ${ }^{21}$ The discrepancies between the results of the previous United Kingdom studies and the present study are likely to be mainly related to different methodologies (especially the methods used to identify cases), rather than true differences in incidence. We used extensive searches, including reviewing all $\mathrm{CT}$, to iden- tify all cases in a defined area of Scotland. In comparison, the previous studies were either restricted to patients admitted to a single hospital department, ${ }^{12}{ }^{14}$ or performed before CT was available. ${ }^{13}$

Despite the extensive searches that were used to identify all incident cases of intracranial tumour in this study, it is very possible that some cases were missed. In particular, the study was not prospective, and so difficulties were encountered in tracing the notes and scans of some patients with possible tumours (23 patients were excluded on this basis). The decrease in incidence in very elderly people may be because cases were missed in this age group due to underinvestigation and diagnostic bias. General practitioner records were not used to identify patients and therefore some patients who were either not admitted to hospital or admitted to a hospital outside the study region may not have been identified (none of the patients identified from the Cancer Registry were admitted to hospitals outside the region, however). Death certificates were also not specifically screened during the study although they were monitored by the Scottish Cancer Registry. Very few asymptomatic patients were identified during the study. The few asymptomatic patients included was probably due to the low necropsy rate during the study period-less than $15 \%$ of patients who die in Scotland have a necropsy (General Register Office, personal communication). Previous studies have suggested that asymptomatic gliomas are found in about $0.5 \%$ of necropsies in those aged over 65 years, ${ }^{22}$ that asymptomatic meningiomas are found in about $1 \%-2 \%$ of all necropsies, ${ }^{22}{ }^{23}$ and that secondary intracranial tumours are found in up to $40 \%$ of necropsies in patients with certain types of cancer. ${ }^{24}$ Also, necropsy reports were not routinely screened during the study period and not all necropsies that were performed included an examination of the CNS. This could have been improved if the 
study had been prospective and pathologists had been informed of the need for examination of the CNS.

Although only $41 \%$ of patients had histology, it is unlikely that we included many patients who did not, in fact, have an intracranial tumour. All scans were reviewed by two radiologists to confirm the diagnosis, and the notes were reviewed to make sure no other diagnosis came to light during follow up. A previous study showed that about $3 \%$ of those with a CT diagnosis of an intracranial tumour had some other pathology on biopsy, ${ }^{17}$ which would mean that only four patients in this study may not have had a tumour. Even when histology is available, misclassification can occur. In one study from America, $2 \%$ of intracranial tumours diagnosed on histology proved not to have a tumour on expert review. ${ }^{25}$ However, as all biopsies in this study were reported by one of three pathologists in a regional neuropathology centre, no further review of the histology was undertaken. Overall, therefore, the total incidence figures reported in the study are, if anything, likely to be an underestimate of the true incidence given the low number of asymptomatic patients identified and the difficulty in identifying patients retrospectively. The lack of histology did hinder classification of the tumours into the different WHO types, and it is likely that the incidences of tumour types are not as accurate as the incidence figures for all primary and secondary tumours.

About $50 \%$ of all intracranial tumours were metastases, which is the highest proportion that has been reported from any incidence study. ${ }^{132126}$ The primary tumour was a lung cancer in about $50 \%$ of cases. Neuroepithelial tumours (mainly gliomas) were the commonest type of primary intracranial tumour, accounting for about $50 \%$ of all primary tumours. Primary CNS lymphomas were uncommon and, although it has been claimed recently that the incidence of primary CNS lymphoma in south east Scotland has increased dramatically since the late $1980 \mathrm{~s}^{27}$ there were too few cases in this study to confirm this.

The incidence of intracranial tumours increased markedly with age up to 75 years (10-fold for primary tumours, 20 -fold for secondary tumours), but then seemed to decrease in the very oldest patients. This decrease is likely to be an artefact due to chance (few cases were identified in people aged over 75 years) and bias. Elderly patients may be less likely to present themselves to a doctor if they have symptoms of an intracranial tumour, and may also be less likely to be referred for CT or to have a necropsy if they died. There may also be a diagnostic bias in the very elderly: patients with intracranial symptoms or signs may be diagnosed as having a stroke rather than a tumour, particularly if they did not have CT. A recent audit of stroke patients in the Western General Hospital showed that only $20 \%$ of patients admitted to the care of geriatricians had CT compared with $80 \%$ of those admitted to the care of general physicians ( $M$
Dennis, personal communication). One previous study from an area with a very high necropsy rate in the general population (which partly overcomes referral and diagnostic bias) showed that the incidence of meningeal tumours increased in all age groups but that the incidence of neuroepithelial tumours decreased in those aged over 85 years. ${ }^{10}$

There were too few patients with each tumour type to reliably determine the relative incidences in male and female patients. Generally, however, there seemed to be little difference between the sexes except for meningeal tumours which were about twice as common in female as in male patients. The relation between the incidence of neuroepithelial tumours and socioeconomic status is interesting. For most other cancers the incidence has been shown to be higher in people with low socioeconomic status, ${ }^{19}$ which explains why, in this study, the incidence of secondary intracranial tumours increased with decreasing socioeconomic status. However, for neuroepithelial tumours the incidence decreased in people with lower socioeconomic status. This was unlikely to be a chance finding as a similar inverse relation was found in the Scottish Cancer Registry when over 3000 "brain and other CNS" tumours were analysed, ${ }^{19}$ and in neuroepithelial tumours in children. ${ }^{28}$ The incidence rates for each socioeconomic group were not standardised for age, and therefore part of the explanation for the decrease in incidence may be that less affluent groups contained fewer elderly people, in whom the incidence is higher. However, this is unlikely to explain the twofold difference in incidence that was found. Referral bias may mean that patients from deprived areas are less likely to present to doctors or to be referred for investigation but most neuroepithelial tumours present with severe and progressive symptoms and signs which patients and doctors would find difficult to ignore. It is also unlikely that there was selective misclassification of neuroepithelial tumours - that is, that tumours in people from affluent areas were more often misdiagnosed as neuroepithelial. However, there could be misclassification of the socioeconomic status of the patient as this was based on the postcode of residence rather than on the actual socioeconomic status. Not all people living in a postcode sector with a particular deprivation category will have the same socioeconomic status. However, it might be expected that such misclassification would be most pronounced in areas with intermediate deprivation categories (categories 3, 4, and 5) rather than in areas of the greatest affluence. The association between high socioeconomic status and the increased incidence of neuroepithelial tumours could, therefore, be real.

In summary, the incidence of primary and secondary intracranial tumours in the United Kingdom is probably significantly higher than was previously thought. If the results of this study are confirmed, primary intracranial tumours would be the sixth most common tumour in both males and females in Scotland. ${ }^{19}$ The prognosis of most types of 
primary intracranial tumour and of secondary tumours is very poor and has changed little over the past 10 years. ${ }^{29}$ There is, therefore, an urgent need for a coordinated approach among the many different specialties involved in the care of these patients (paediatrics, neurology, neurosurgery, oncology, and general medicine) to further research into the aetiology and treatment of intracranial tumours.

We thank all clinicians involved in the care of these patients and who helped to identify them, in particular Dr A Grego (oncology), Mr I R Whittle (neurosurgery), and Dr J W Ironside (neuropathology). We also thank Dr Peter Rothwell who helped extract data from case notes; Mr Stuart Griffen (audit assistant) who helped trace many of the case notes; and Mr Jim Slattery for statistical advice. This project was made possible by a grant from the Lothian Medical Audit Committee. CC was supported by a Wellcome Trust research training fellowship in clinical epidemiology.

\section{Appendix 1: the Carstairs score}

The Carstairs score is based on the following variables, which are obtained from census data:

(1) Overcrowding: the proportion of people living in private households with a density of $>1$ person per room.

(2) Male unemployment: the proportion of economically active males seeking or waiting to start work.

(3) Low social class: the proportion of people in private households whose economically active head is in social class 4 or 5 .

(4) Car ownership: the proportion of people in private households who do not own a car.

Appendix 2: International Classification of Diseases (version 9) codes relevant to intracranial tumours

191 Malignant neoplasms of brain

192 Malignant neoplasm of other and unspecified parts of nervous system

192.0 Cranial nerves

192.1 Cerebral meninges

$192 \cdot 8$ Other

192.9 Part unspecified

194 Malignant neoplasm of other endocrine glands and related structures

194.3 Pituitary and craniopharyngeal duct

194.4 Pineal gland

198 Secondary neoplasm of other specified parts

198.3 Brain and spinal cord

198.4 Other parts of nervous system (meninges)

225 Benign neoplasm of brain and other parts of

nervous system

225.0 Brain

225.1 Cranial nerves

225.2 Cerebral meninges

225.8 Other

225.9 Part unspecified

227 Benign neoplasm of other endocrine glands

and related structures

227.3 Pituitary and craniopharyngeal duct

227.4 Pineal gland

237 Neoplasm of uncertain behaviour of

endocrine glands and nervous system

237.0 Pituitary and craniopharyngeal duct

237.1 Pineal gland

237.5 Brain and spinal cord

237.6 Meninges

237.9 Cranial nerves

239 Neoplasm of unspecified nature

239.6 Brain

239.7 Other parts of nervous system (cranial nerves, meninges)

253 Disorders of pituitary gland and hypothalamic control
253.0 Acromegaly and gigantism

253.1 Other anterior pituitary hyperfunction

1 Doll R, Peto R. The causes of cancer: quantitative estimates of avoidable risks of cancer in the United States today. F Natl Cancer Inst 1981;66:1 191-308

2 Jensen OM, Storm HH. Purposes and uses of cancer registration. In: Jensen OM, Parkin DM, MacLennan R Muir CS, Skeet RG, eds. Cancer registration: principles and methods. Lyons: International Agency for Research on Cancer, 1991:7-21.

3 Ben-Schlomo Y, Davey Smith G. Brain tumour trends [letter]. Lancet 1989;2:1272-3.

4 Davis DL, Hoel D, Percy C, Ahlbom A, Schwartz J. Is brain cancer mortality increasing in industrial countries? Ann N Y Acad Sci 1990;609:191-204.

5 Greig NH, Ries LG, Yancik R, Rapoport SI. Increasing annual incidence of primary malignant brain tumors in annual incidence of primary malignant brain

6 Mao Y, Desmeules M, Semenciw H, Hill G, Gaudette L, Wigle DT. Increasing brain cancer rates in Canada. Can Med Assoc f 1991;145:1583-91.

7 Modan B, Wagener DK, Feldman JJ, Rosenberg HM, Feinleib $M$. Increased mortality from brain tumors: a combined outcome of diagnostic technology and change of attitude toward the elderly. Am ₹ Epidemiol 1992;135: 1349-57.

8 Schoenberg BS, Christine BW, Whisnant JP. The resolution of discrepancies in the reported incidence of primary brain tumors. Neurology 1978;28:817-23.

9 Boyle P, Maisonneuve P, Saracci R, Muir CS. Is the increased incidence of primary malignant brain tumors in the elderly real? $₹$ Natl Cancer Inst 1990;82:1594-6.

10 Radhakrishnan K, Mokri B, Parisi JE, O'Fallon M, Sunku J, Kurland LT. The trends in incidence of primary brain tumors in the population of Rochester, Minnesota. Ann

11 Polednak AP. Time trends in incidence of brain and central nervous system cancers in Connecticut. $\mathcal{F}$ Natl Cancer Inst 1991;83:1679-81.

12 Barker DJP, Weller RO, Garfield JS. Epidemiology of primary tumours of the brain and spinal cord: a regional survey in southern England. $f$ Neurol Neurosurg Psychiatry 1976;39:290-6.

13 Brewis M, Poskanzer DC, Rolland C, Miller H. Neurological diseases in an English city. Acta Neurol Scand 1966;42(suppl 24):1-89.

14 Cole GC, Wilkins PR, West RR. An epidemiological survey of primary tumours of the brain and spinal cord in south of primary tumours of the brain and spinal
east Wales. Br $\mathcal{N}$ Neurosurg 1989;3:487-94.

15 Grant $R$, Collie D, Counsell C. The incidence of cerebral glioma in the working population: a forgotten cancer? $\mathrm{Br} \mathcal{F}$

16 Kleihues P, Burger PC, Scheithauer BW, in collaboration with LH Sobin and pathologists in 14 countries. World Health Organisation international histological classification of tumours. Histological typing of tumours of the central nervous system. Berlin: Springer-Verlag, 1993.

17 Todd NV, McDonagh T, Miller JD. What follows diagnosis by computed tomography of solitary brain tumours? Audit of one year's experience in south east Scotland. Lancet 1987;1:611-2.

18 Franzani A, Leocata F, Giorgi C, Allegranza A, Servello D Broggi G. Role of stereotactic biopsy in multifocal brain lesions: considerations on 100 consecutive cases. $f$ Neurol Neurosurg Psychiatry 1994;57:957-60.

19 Sharp L, Black RJ, Harkness EF, Finlayson AR, Muir CS Cancer registration statistics in Scotland: 1981-1990. Edinburgh: ISD Publications, 1993.

20 McLoone P. Carstairs scores for Scottish postcode sectors from the 1991 census. Glasgow: Public Health Research Unit, University of Glasgow, 1993

21 D'Alessandro G, Di Giovanni M, Iannizzi L, Guidetti E Bottacchi E. Epidemiology of primary intracrania tumors in the Valle d'Aosta (Italy) during the 6-year period 1986-1991. Neuroepidemiology 1995;14:139-46.

22 Annegers JF, Schoenberg BS, Okazaki H, Kurland IT Epidemiologic study of primary intracranial neoplasms. Arch Neurol 1981;38:217-9.

23 Nakasu S, Hirano A, Shimura T, Llena JF. Incidental meningiomas in autopsy study. Surg Neurol 1987;27: 319-22.

24 Burgess RE, Burgess VF, Dibella NJ. Brain metastases in small cell carcinoma of the lung. $¥ A M A$ 1979;242. 2084-6.

25 Armstrong DA, Almes MJ, Buffler P, Frankowski F, McGarry P. A cluster classification for histologic diagnosis of CNS tumors in an epidemiologic study. Neuroepidemiology 1990;9:2-16.

26 Fogelholm R, Uutela T, Murros K. Epidemiology of central nervous system neoplasms. A regional survey in central Finland. Acta Neurol Scand 1984;69:129-36.

27 O'Sullivan MG, Whittle IR, Gregor A, Ironside JW. Increasing incidence of CNS primary lymphoma in south-east Scotland [letter]. Lancet 1991;338:895-6.

28 McKinney PA, Ironside JW, Harkness EF, Arango JC Doyle D, Black RJ. Registration quality and descriptive epidemiology of childhood brain tumours in Scotland $B r$ f Cancer 1994;70:973-9.

29 Black RJ, Sharp L, Kendrick SW. Trends in cancer survival in Scotland. 1968-1990. Edinburgh: ISD Publications, 1993. 